\title{
Saikosaponin a, an active compound of Radix Bupleuri, attenuates inflammation in hypertrophied 3T3-L1 adipocytes via ERK/NF-KB signaling pathways
}

\author{
SUNG OK KIM $^{1}$, JI YEOUNG PARK ${ }^{1}$, SEO YOUNG JEON ${ }^{1}$, CHEA HA YANG ${ }^{2}$ and MI RYEO KIM ${ }^{1}$ \\ Departments of ${ }^{1}$ Herbal Pharmacology and ${ }^{2}$ Physiology, College of Oriental Medicine, \\ Daegu Haany University, Suseong-gu, Daegu 706-828, Republic of Korea
}

Received May 30, 2014; Accepted January 19, 2015

DOI: 10.3892/ijmm.2015.2093

\begin{abstract}
Bupleurum falcatum L. is employed in oriental medicine in Korea. This root has been used for anti-inflammatory, anti-pyretic, and anti-hepatotoxic effects in the treatments of common cold, fever, and hepatitis. One of major bioactive compounds of Radix Bupleuri is the saikosaponin a (SSNa). However, little is known concerning the effects of SSNa on obesity associated with a state of low-grade inflammation. Consequently, this study was conducted to determine the inhibition of the inflammation pathway of SSNa in obesity. MTT assay was conducted for cytotoxicity and viability; nuclear and cytoplasmic fractions were extracted from adipocytes for translocation of nuclear factor- $\mathrm{kB}$ cells $(\mathrm{NF}-\kappa \mathrm{B})$; nitric oxide (NO) production and secretion using Griess reagent; reverse transcription-polymerase chain reaction (RT-PCR) and immunoblotting for mRNA and protein levels associated with inflammation in the hypertrophied adipocytes. The results revealed that SSNa significantly decreased the expression of tumor necrosis factor- $\alpha$ (TNF $\alpha$ ), interleukin (IL)-1 $\beta$ and IL-6 as proinflammatory cytokines, compared to that of non-treated control cells. Inducible nitric oxide synthase (iNOS) and cyclooxygenase-2 (COX-2) as inflammatory factors were reduced by treatment of these cells with SSNa and also suppressed NO production. Phosphorylation of I $\mathrm{B} \alpha$ was inhibited and translocation of $\mathrm{NF}-\mathrm{kB}$ was suppressed via the ERK pathway in response to SSNa treatment. In conclusion, the results demonstrated that SSNa can inhibit the expression of inflammatory-associatied genes in hypertrophied 3T3-L1 adipocytes and is a potent inhibitor of NF- $\mathrm{kB}$ activation. Thus these results suggest that
\end{abstract}

Correspondence to: Professor Mi Ryeo Kim, Department of Herbal Pharmacology, College of Oriental Medicine, Daegu Haany University, 165 Sang-dong, Suseong-gu, Daegu 706-828, Republic of Korea

E-mail: mrkim@dhu.ac.kr

Key words: saikosaponin a, inflammation, hypertrophy, adipocytes,

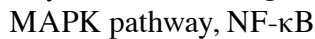

SSNa is a novel therapeutic agent against that can be used against obesity-associated inflammation.

\section{Introduction}

Koreans are 1.5-fold more likely to be obese as compared to 10 years ago, according to the Ministry of Health and Welfare (1). A $>4$-fold increase in health-care expenditure for the treatment of obesity-associated diseases such as diabetes, heart disease, bone disorders and cancer, has been observed. Therefore, obesity is now considered a social concern (http://www.oecd. org/health/prevention. 2012).

Previous findings have conclusively demonstrated that inflammation plays a major role in obesity. Obesity is closely associated with a state of chronic, low-grade inflammation characterized by abnormal cytokine production and activation of the inflammatory signaling pathway in adipose tissues $(2,3)$. Obese inviduals commonly have many elevated markers of inflammation, including major proinflammatory cytokines such as tumor necrosis factor- $\alpha(\mathrm{TNF} \alpha)$, interleukin (IL)-1 $\beta$, IL-6; nitric oxide (NO) production, inducible nitric oxide synthase (iNOS), cyclooxygenase-2 (COX-2) as an immune-associated cytotoxic factor; and transcription factor of nuclear factor- $\kappa \mathrm{B}$ cells (NF- $\kappa \mathrm{B}$ ) through activation of the mitogen-activated protein kinase (MAPK) pathway including ERK, JNK and p38 signaling pathways in obese adipocytes (4-7). Inflammation is a response of a tissue to injury associated with biological, chemical or physical stimuli. It is a defense mechanism aimed to remove the injurious stimuli and initiates the tissue healing process (8). However, an excessive inflammatory response itself constitutes a dilemma. It is also an important pathogenic mediator for the development of obesity. Thus, using bioactive compounds to regulate the expression of inflammatory-associated cytokines is significant in the prevention and treatment of obesity.

Bioactive compound extracts from natural products are known to possess some therapeutic potential for inflammation (9-12). Saikosaponin a (SSNa) is one of the major triterpenoid saponins derived from Bupleurum falcatum L. (13), and has various pharmacological activities such as anti-inflammatory, immunoregulating, antibacterial, antiviral, and anticancer activities (9,14-18). However, the anti-inflammatory effects of 
SSNa, especially the underlying mechanisms in hypertrophied 3T3-L1 adipocytes have not been studied. In the present study, we assessed SSNa control proinflammatory-associated cytokines (TNF $\alpha$, IL-1 $\beta$, and IL-6) and immune-related cytotoxic factors (NO, iNOS, and COX-2) through the NF- $\mathrm{BB}$ signaling pathway in 3T3-L1 hypertrophied adipocytes. In addition, the possible mechanisms involved in the inhibitory responses were examined.

\section{Materials and methods}

Cell and reagents. Mouse embryo fibroblast 3T3-L1 preadipocytes were purchased from the American Type Culture Collection (ATCC; Rockville, MD, USA). High-glucose Dulbecco's modified Eagle's medium (DMEM), bovine calf serum (BCS), fetal bovine serum (FBS) and phosphate-buffered saline (PBS) were purchased from Thermo Fisher Scientific (Waltham, MA, USA). Penicillin/streptomycin (P/S), $0.25 \%$ trypsin/ethylenediaminetetraacetic acid (EDTA), 3-(4,5-dimethylthiazol-2-yl)-2,5-diphenyltetrazolium bromide (MTT), insulin, dexamethasone (DEX), 3-isobutyl-1-methylxanthine (IBMX), dimethyl sulfoxide (DMSO), rosiglitazone, Oil Red O, and sulforaphane, used as the positive control compound, were purchased from Sigma-Aldrich Co. (St. Louis, MO, USA). SSNa was purchased from Wako Pure Chemical industries, Ltd. (Osaka, Japan).

Cell culture. The mouse embryo fibroblast 3T3-L1 cells were obtained from ATCC, and 3T3-L1 preadipocytes were differentiated into mature adipocytes. Briefly, 3T3-L1 preadipocytes were cultured at $37^{\circ} \mathrm{C}$ in a humidified $5 \% \mathrm{CO}_{2}$ atmosphere and grown in DMEM supplemented with $10 \%$ (v/v) BCS, $1 \%$ (v/v) of P/S until confluency was reached. For the induction of differentiation into mature adipocytes, the cells were grown to 4 days post-confluence (0 day). Subsequently, the completely confluent preadipocytes were induced with adipogenic hormone mixture, DMEM medium containing $10 \%(\mathrm{v} / \mathrm{v}) \mathrm{FBS}, 0.5 \mathrm{mM}$ of IBMX, $2 \mu \mathrm{M}$ of DEX, and $2 \mu \mathrm{g} / \mathrm{ml}$ of insulin for 2 days. The cells were then maintained in DMEM containing $10 \% \mathrm{FBS}$ and $2 \mu \mathrm{g} / \mathrm{ml}$ of insulin for 2 days, followed by culturing for an additional 2 weeks, at which time cells reached full differentiation as hypertrophied adipocytes.

Cell viability. Cells $\left(5 \times 10^{4}\right.$ cells $\left./ \mathrm{ml}\right)$ were cultured in a $96-$ well plate. After the supernatants were removed, the cells were treated with $200 \mu \mathrm{l}$ of various concentrations of SSNa for $24 \mathrm{~h}$, and then MTT (5 mg/ml in serum-free medium, $10 \mu \mathrm{l} /$ well) was added. The medium was discarded after $2 \mathrm{~h}$ and the formazan crystals were solubilized in $50 \mu 1$ of DMSO. The optical density was measured at $570 \mathrm{~nm}$ with microplate reader (Tecan Austria GmbH, Grödig, Austria).

NO assay. Hypertrophied 3T3-L1 cells were treated with $100 \mathrm{nM}$ SSNa and $50 \mathrm{nM}$ sulforaphane for $1 \mathrm{~h}$, respectively. The cell supernatants were collected and assayed for NO production using Griess reagent (Molecular Probes, Eugene, OR, USA). Briefly, the samples were mixed with an equal volume of Griess reagent and incubated at room temperature for $10 \mathrm{~min}$. The absorbance was measured at $570 \mathrm{~nm}$ on a microplate reader. Sodium nitrite $(0-100 \mu \mathrm{M})$ was used as a standard to assess nitrite concentrations.

Reverse transcription-polymerase chain reaction (RT-PCR). Total-RNA was prepared using TRIzol reagent (Invitrogen, Carlsbad, CA, USA) according to the manufacturer's instructions, and was then used for RT-PCR with one step RT-PCR premix (Intron Biotechnology Co., Seongnam, Korea) according to the manufacturer's instructions. PCR was carried out in a Mastercycler (Eppendorf, Hamburg, Germany) with the primers indicated in Table I. Conditions for PCR were $1 \mathrm{x}\left(94^{\circ} \mathrm{C}\right.$ for $\left.3 \mathrm{~min}\right) ; 35 \mathrm{x}\left(94^{\circ} \mathrm{C}\right.$ for $45 \mathrm{sec} ; 58^{\circ} \mathrm{C}$ for $45 \mathrm{sec}$; and $72^{\circ} \mathrm{C}$ for $\left.1 \mathrm{~min}\right)$, and $1 \mathrm{x}\left(72^{\circ} \mathrm{C}\right.$ for $\left.10 \mathrm{~min}\right)$. As a control of sample loading and normalization between samples, PCR amplification of the housekeeping gene, glyceraldehyde 3-phosphate dehydrogenase $(G A P D H)$, was included for each sample at each run. GAPDH was used as an internal control. Amplification products obtained by PCR were electrophoretically separated on $1.5 \%$ agarose gel and visualized by ethidium bromide (Sigma-Aldrich Co.) staining.

Western blot analysis. After the differentiated 3T3-L1 cells were harvested, total protein lysates were prepared and ice-cold lysis buffer was added. The supernatant was obtained following centrifugation at $9,000 \times \mathrm{g}$ for $15 \mathrm{~min}$ at $4^{\circ} \mathrm{C}$. Cytoplasmic proteins were separated from the nuclear fraction using a NE-PER Nuclear and Cytoplasmic Extraction kit (Pierce, Rockford, IL, USA). $\beta$-actin was used as an internal control for the cytosolic fraction and lamin A (Table II) was applied as an internal control for the nuclear fraction. The protein concentrations were determined by the Bradford assay (Bio-Rad protein assay; Hercules, CA, USA). The proteins were separated by SDS-PAGE and electrophoretically transferred to polyvinylidene fluoride (PVDF; Millipore, Billerica, MA, USA) membranes. Non-specific binding was blocked by $1-\mathrm{h}$ incubation of the membranes in 5\% (w/v) non-fat dry milk (or $5 \%$ BSA) in Tris-buffered saline ( $\mathrm{pH} 7.5)$. The blots were then incubated overnight with primary antibodies (Table II) in the antibody buffer containing $1 \%(\mathrm{w} / \mathrm{v})$ non-fat dry milk in $0.05 \%$ (v/v) Tween-20 in Tris-buffered saline (TBST), washed three times with TBST, and incubated for $1 \mathrm{~h}$ with a peroxidase-labeled secondary antibody in the antibody buffer. The blots were developed for visualization using an enhanced chemiluminescence detection kit (Pierce).

Statistical analysis. Data were presented as \pm standard error of the mean (SEM). Statistical analysis was performed using the Student's t-test and GraphPad Prism 5 (GraphPad Software, Inc., La Jolla, CA, USA). Significance was set at $\mathrm{p} \leq 0.05$. Band intensities in the immunoblots were quantified by densitometry using L Process (Version 2.01; Fujifilm, Stamford, CT, USA) and Multi Gauge software (Version 2.02; Fujifilm). Band intensities were normalized relative to the internal control and background. Multiple experiments were combined and all the experiments were repeated a minimum of three times.

\section{Results}

SSNa does not affect cytotoxicity of 3T3-L1 cells. The metabolic-dye-based MTT assay was performed to determine the 
Table I. Oligonucleotide sequence used in PCR.

\begin{tabular}{|c|c|c|}
\hline Name & $\begin{array}{l}\text { Sequence of } \\
\text { primers }(5 \rightarrow 3)\end{array}$ & $\begin{array}{l}\text { Annealing } \\
\text { temp }\left({ }^{\circ} \mathrm{C}\right)\end{array}$ \\
\hline $\mathrm{TNF} \alpha$ & $\begin{array}{l}\text { F: ACGGCATGGATCTCAAAGAC } \\
\text { R: GTGGGTGAGGAGCACGTAGT }\end{array}$ & 58 \\
\hline IL-6 & $\begin{array}{l}\text { F: AGTTGCCTTCTTGGGACTGA } \\
\text { R: CAGAATTGCCATTGCACAAC }\end{array}$ & 58 \\
\hline iNOS & $\begin{array}{l}\text { F: CTC CTT CAA AGA GGC AAA AAT A } \\
\text { R: CAC TTC CTC CAG GAT GTT GT }\end{array}$ & 54 \\
\hline $\mathrm{NF}-\kappa \mathrm{B}$ & $\begin{array}{l}\text { F: GCACGAGGCTCCTTTTCTCAA } \\
\text { R: CGTTTTTCTTCAATCCGGTGG }\end{array}$ & 53 \\
\hline IL-1 $\beta$ & $\begin{array}{l}\text { F: GCT GAC AGA CCC CAA AAG ATT } \\
\text { R: TGTGCAGACTCA AACTCC АCTT }\end{array}$ & 55 \\
\hline $\mathrm{COX}-2$ & $\begin{array}{l}\text { F: CATTCTTTGCCCAGCACTTC } \\
\text { R: CCTGAGTGTCTTTGACTGTG }\end{array}$ & 54 \\
\hline GAPDH & $\begin{array}{l}\text { F: TGCCTВCTTCACCACCTTC } \\
\text { R: TGCCTCCTGCACCACCAАCT }\end{array}$ & 53 \\
\hline
\end{tabular}

Table II. List of antibodies used in western blot analysis.

\begin{tabular}{|c|c|c|}
\hline $\begin{array}{l}\text { Primary } \\
\text { antibodies }\end{array}$ & $\begin{array}{l}\text { Antibody } \\
\text { information }\end{array}$ & $\begin{array}{r}\text { Dilution } \\
\text { factor }\end{array}$ \\
\hline $\mathrm{TNF} \alpha$ & Santa Cruz Biotechnology, Inc. & $1: 500$ \\
\hline IL-6 & Santa Cruz Biotechnology, Inc. & $1: 500$ \\
\hline IL-1 $\beta$ & Millipore & $1: 500$ \\
\hline iNOS & Santa Cruz Biotechnology, Inc. & $1: 1,000$ \\
\hline COX-2 & Santa Cruz Biotechnology, Inc. & $1: 1,000$ \\
\hline $\mathrm{I} \kappa \mathrm{B} \alpha$ & Santa Cruz Biotechnology, Inc. & $1: 1,000$ \\
\hline $\mathrm{pI \kappa \textrm {B }} \alpha$ & Santa Cruz Biotechnology, Inc. & $1: 1,000$ \\
\hline $\mathrm{NF}-\kappa \mathrm{B}$ p 65 & Santa Cruz Biotechnology, Inc. & $1: 1,000$ \\
\hline $\mathrm{NF}-\kappa \mathrm{B}$ p50 & Santa Cruz Biotechnology, Inc. & $1: 1,000$ \\
\hline$\beta$-actin & Santa Cruz Biotechnology, Inc. & $1: 1,000$ \\
\hline Lamin A & Santa Cruz Biotechnology, Inc. & $1: 1,000$ \\
\hline ERK & Cell Signaling Technology, Inc. & $1: 1,000$ \\
\hline pERK & Cell Signaling Technology, Inc. & $1: 1,000$ \\
\hline
\end{tabular}

cytotoxicity of SSNa on 3T3-L1 cells with 0-1 $\mu \mathrm{M}$ SSNa. No cytotoxicity on 3T3-L1 cells was observed at the concentration of 0-1 $\mu \mathrm{M} \mathrm{SSNa} \mathrm{(Fig.} \mathrm{1).} \mathrm{Therefore,} 100 \mathrm{nM} \mathrm{SSNa}$ was used for treatments in this experiment. This concentration did not inhibit cell growth and cytotoxicity compared to that of the control.

SSNa suppresses NO production. To determine the effect of SSNa on NO production and iNOS expression, 3T3-L1 hypertrophied adipocytes were treated with $\mathrm{SSNa}(100 \mathrm{nM})$ for $1 \mathrm{~h}$. The culture medium from the cells was collected and assayed for NO generation using the Griess reagent assay. The production of NO in hypertrophied cells increased in the medium by $\sim 5$-fold $(26.3 \pm 2.8 \mu \mathrm{M})$ compared to that of preadipocytes $(5.3 \pm 2.1 \mu \mathrm{M})$ (Fig. 2A). However, treatment with SSNa mark-

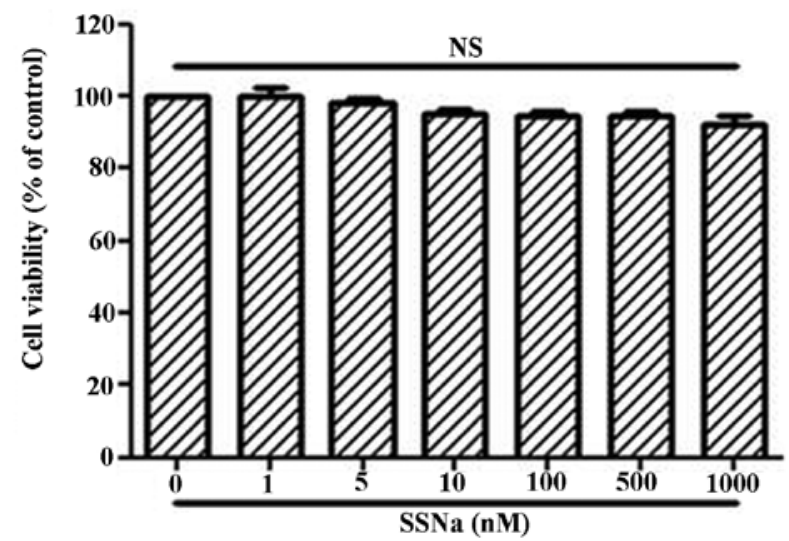

Figure 1. Effect of saikosaponin a (SSNa) on cell viability in 3T3-L1 cells. Cells were seeded in a 96-well plate and grown for one day. The cell viability was measured by the metabolic-dye-based 3-(4,5-dimethylthiazol-2-yl)-2,5-diphenyltetrazolium bromide (MTT) assay. Results are expressed as a percentage of the vehicle-treated control \pm standard error of the mean (SEM) of three separate experiments. Statistical significance (Student's t-test) analyses were performed using GraphPad Prism 5. NS, no significance.

edly attenuated NO generation, such that the concentration was only $15.2 \pm 1.3 \mu \mathrm{M}$. Thus, we assessed whether SSNa of NO production was associated with iNOS mRNA and protein levels. As expected, treatment of SSNa significantly decreased excessive iNOS mRNA (Fig. 2B) and protein expressions (Fig. 2C) compared with those of the control cells. These results showed that excessive lipogenesis significantly induces NO generation and iNOS expression. However, SSNa suppressed NO production by inhibiting iNOS expression in hypertrophied adipocytes.

Downregulation of levels of proinflammatory mediator genes. To determine whether SSNa inhibits the production of TNF $\alpha$, IL-6, IL-1 $\beta$, COX-2 and NF- $\mathrm{B}$, RT-PCR and immunoblot analysis were performed on 3T3-L1 hypertrophied adipocytes. As shown in Fig. 3, mRNA and protein levels of TNFa, IL-6 and IL-1 $\beta$ as proinflammatory cytokines were significantly reduced by SSNa in the cells $(\mathrm{p}<0.05)$ compared to those of the control. Tho mRNA and protein levels of inflammatory factor COX-2 were also reduced by the treatment of SSNa compared to those of the control. SSNa also strongly prevented the expression of NF- $\mathrm{NB}$, a central role in general inflammatory 3T3-L1 hypertriphied adipocytes compared to that of control $(\mathrm{p}<0.05)$.

Suppression of $N F-\kappa B$ activation. We investigated whether SSNa prevents the expression of $\mathrm{NF}-\kappa \mathrm{B}$ (p65 and p50) in hypertrophied adipocytes. As shown in Fig. 4A, NF- $\mathrm{B}$ (p65 and p50) was highly expressed in non-treated 3T3-L1 cells whereas SSNa-treated cells were significantly decreased $(\mathrm{p}<0.05)$. Following treatment with SSNa, phosphorylation of I $\mathrm{B}$ and ERK was significantly decreased compared to that of the controls. To confirm the effects of SSNa on the prevention of $\mathrm{NF}-\kappa \mathrm{B}$ translocation from the cytosol to the cell nucleus in fully mature 3T3-L1 adipocytes, the expression of NF- $\kappa \mathrm{B}$ in the cytosol and nucleus were analyzed using immunoblots. As shown in Fig. 4B, translocation of NF- $\kappa \mathrm{B}$ (p65 and p50) was decreased in 3T3-L1 cell nucleus treated with $100 \mathrm{nM}$ SSNa compared to that of the controls. Consequently, $\mathrm{SSNa}$ inhibited the translocation of NF- $\kappa \mathrm{B}$ from the cytosol to the nucleus by inhibiting the degradation of $\mathrm{I} \kappa \mathrm{B} \alpha$ in cytoplasm. 

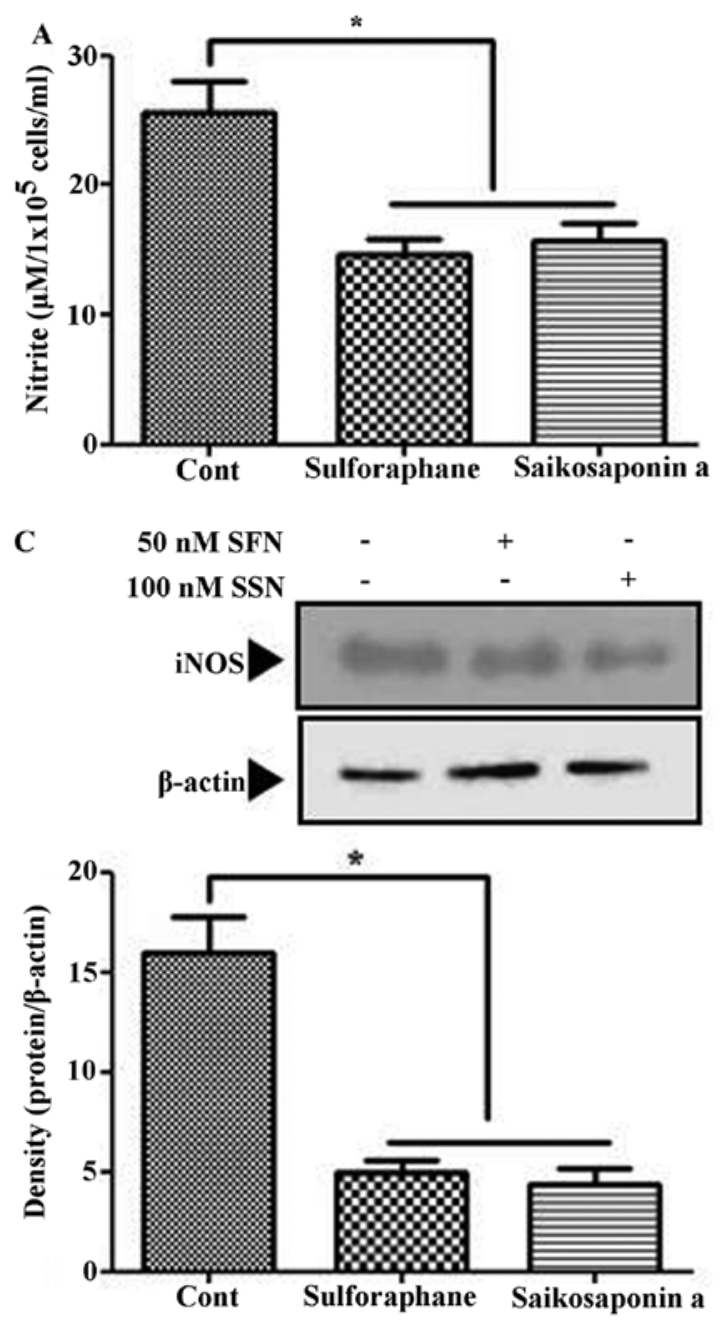

Inhibition of ERK axis. To confirm SSNa-suppressed translocation of $\mathrm{NF}-\kappa \mathrm{B}$ through phosphorylation of ERK as a TNF $\alpha$ downstream, U0126 as ERK inhibitor was pretreated in 3T3-L1 adipocytes for $1 \mathrm{~h}$. Phosphorylation of ERK was inhibited compared to that of the controla and that of NF- $\kappa \mathrm{B}$ was also significantly inhibited in 3T3-L1 cell nucleus pretreated with U0126 compound (Fig. 5). Therefore, SSNa controlled the suppression of phosphorylation of ERK, suggesting that SSNa-suppressed inflammation is associated with $N F-\kappa B$ via the ERK signaling pathway in 3T3-L1 adipocytes.

\section{Discussion}

Obesity is a chronic disease and its prevalence is on the increase worldwide (http://www.oecd.org/health/prevention. 2012). Obesity is an important risk factor for various diseases such as cardiovascular diseases, type 2 diabetes by hyperglycemia and insulin resistance, dyslipidemia and hypertension (19-21). It is an abnormal condition accumulating lipid in adipose tissues, which produce and secrete adipokines (TNF $\alpha$, IL-1 $\beta$, IL-6, leptin, resistin and adiponectin) closely involved with inflammation $(22,23)$. Thus, prevention of obesity and adopting a healthy lifestyle is crucial. Consequently, studies on pharmaceutical natural compounds associated with the prevention of obesity are on the increase. In this study, we demonstrated that SSNa has inhibitory effects on the induction and secre-

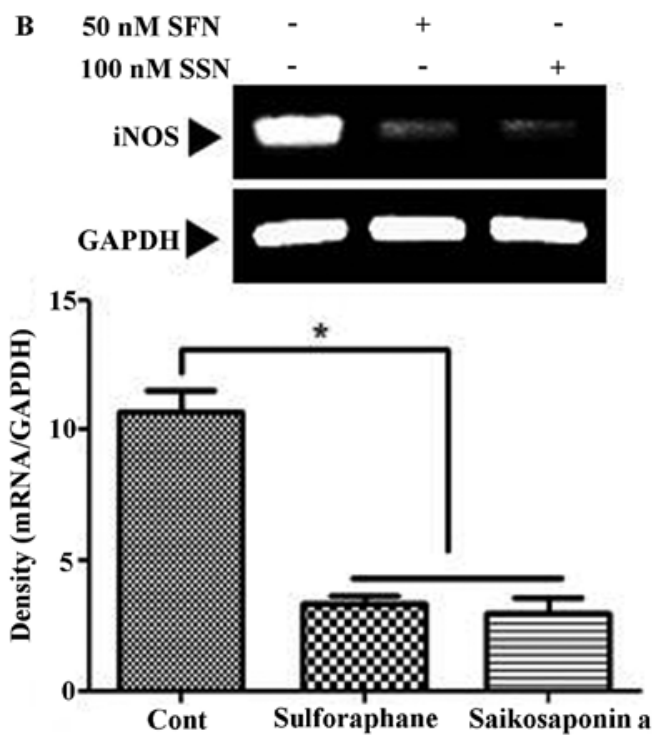

Figure 2. Effect of saikosaponin a (SSNa) on nitric oxide (NO) production and expression of inducible nitric oxide synthase (iNOS) in the 3T3-L1 cells. The cells $\left(5 \times 10^{5}\right.$ cells $\left./ \mathrm{ml}\right)$ were cultured in diffentiated culture medium until hypertrophied adipocytes were formed and incubated with $100 \mathrm{nM}$ concentrations of SSNa for $1 \mathrm{~h}$. (A) Culture supernatants were analyzed for nitrite production at $24 \mathrm{~h}$. The amounts of NO were determined using Griess reagent in the culture medium. (B) Following treatment with SSNa for $1 \mathrm{~h}$, total RNA was isolated and subjected to reverse transcription-polymerase chain reaction (RT-PCR) and the final PCR product was resolved using 1.5\% agarose gel electrophoresis. (C) Cell lysates were analyzed by western blot analysis. Glyceraldehyde 3-phosphate dehydrogenase $(G A P D H)$ and $\beta$-actin were used as an internal control for RT-PCR and western blot analysis, respectively. Band intensities were quantified by densitometry using L Process and Multi Gauge software. Statistical significance (Student's t-test) analyses were performed using GraphPad Prism 5 ( ${ }^{*} \mathrm{p}<0.05$ vs. the control). Each value indicates the mean \pm standard error of the mean (SEM) and is representative of results obtained from three independent experiments.

tion of adipokines to modulate proinflammatory cytokines and inflammatory factors in 3T3-L1 hypertrophied cells that accumulated complete large lipid droplets.

Inflammatory mediator NO generated by iNOS in adipocyte-cultured media treated with $100 \mathrm{nM}$ SSNa was significantly decreased compared to that of the controla and the mRNA and protein level of iNOS was decreased. This result shows that SSNa inhibits NO production through suppression of iNOS expression in 3T3-L1 hypertrophied cells. COX-2, an inflammatory biomarker, is activated to produce prostaglandins as potent lipid mediators, such as PGE2 and is involved in the regulation of neurodegeneration, inflammation and cancer $(24,25)$. Accordingly, decreases in the level of COX-2 have been considered as a therapeutic effect on inflammation $(26,27)$. Results of the COX-2 mRNA and protein revealed that treatment with $\mathrm{SSNa}$ resulted in a significantly inhibited expression of COX-2 protein. Consequently, $\mathrm{SSNa}$ is useful in exerting an inflammatory therapeutic effect in obesity-induced inflammatory diseases. Lu et al reported that $\mathrm{SSa}$ and $\mathrm{SSd}$ significantly inhibited the expression of iNOS and COX-2 in LPS-induced RAW264.7 cells (9). Results of that study support our findings showing that, SSNa plays inhibitory roles in the inflammation effect of 3T3-L1 hypertrophied adipocyte cells.

Fat tissue is not a simple energy storage organ but rather exerts important endocrine and immune functions (2). These functions are achieved primarily through the release of adipo- 

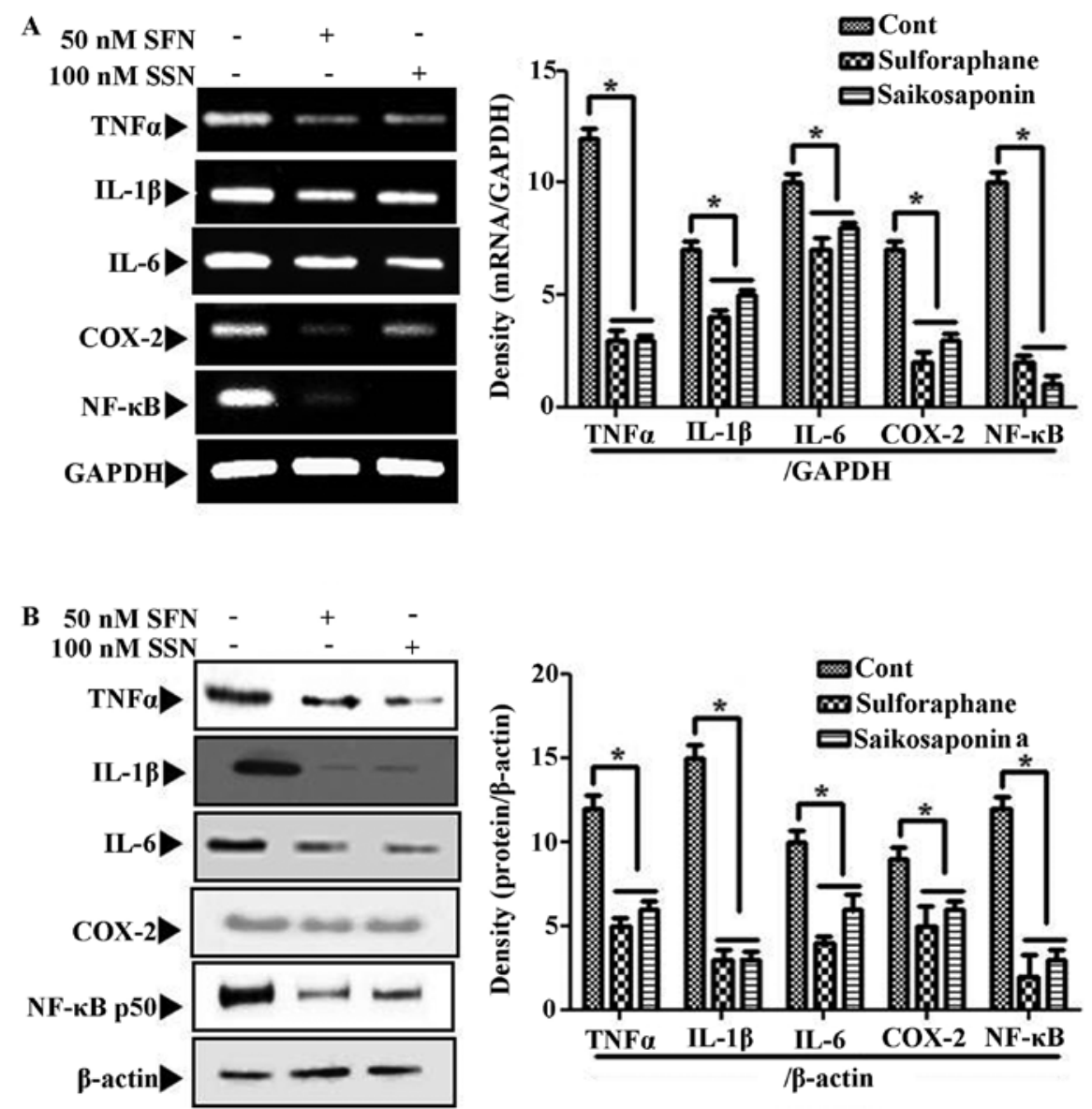

Figure 3. Effect of saikosaponin a (SSNa) on expression of tumor necrosis factor- $\alpha$ (TNF $\alpha$ ), IL-6, IL-1 $\beta$, and cyclooxygenase-2 (COX-2) in the 3T3-L1 hypertrophied adipocytes. (A) Following treatment with SSNa for $1 \mathrm{~h}$, total RNA was isolated and subjected to reverse transcription-polymerase chain reaction (RT-PCR) and the final PCR product was resolved using 1.5\% agarose gel electrophoresis. (B) Cell lysates were analyzed by western blot analysis. Glyceraldehyde 3-phosphate dehydrogenase $(G A P D H)$ and $\beta$-actin were used as an internal control for RT-PCR and western blot analysis, respectively. Band intensities were quantified by densitometry using L Process and Multi Gauge software. Statistical significance (Student's t-test) analyses were performed using GraphPad Prism 5 ("p<0.05 vs. the untreated control). Each value indicates the mean \pm standard error of the mean (SEM) and is representative of results obtained from three independent experiments.

cytokines by white adipose tissues (WAT), which include leptin, resistin, adiponectin and inflammatory cytokines as TNFa, IL-6, monocyte chemotactic protein (MCP)-1, and IL-1. These cytokines and chemokines are critically involved in insulin resistance and chronic inflammation $(19,20)$. Evidence suggesta that TNF $\alpha$ is a major mediator of inflammation in general and of obesity and insulin resistance in particular. TNF $\alpha$ and IL-6 also increase lipolysis and are involved in hypertriglyceridemia and increased serum FFA levels associated with obesity $(28,29)$. Abe $e t$ al reported that saikosaponin $(10 \mathrm{mg} / \mathrm{kg}$ x 4 days) decreased the increase in triglyceride and body weights in the rat (30). Those reports support that obesity-accumulated excessive body fat can be prevented by inhibition of inflammation treated with SSNa. Wang et al showed that curcumin suppressed the transcription and secretion of TNF $\alpha$ and IL-6 induced by palmitate through inhibition of the activation of NF- $\mathrm{KB}$ in 3T3-L1 adipocytes (31). Gonzales and Orlando examined the effect of curcumin on NF- $\kappa \mathrm{B}$ and on the expression of NF- $\kappa \mathrm{B}$-regulated gene products for TNF $\alpha$, IL-6, and COX-2 in adipocytes (32). Treatment of TNF $\alpha$ activated NF- $\kappa B$ signaling, IL-1 $\beta$, IL-6 and COX-2 in differentiated adipocytes. We demonstrated that SSNa significantly decreased pro-inflammatory cytokines such as TNF $\alpha$, IL-1 $\beta$ and IL-6 in 3T3-L1 hypertrophied cells. These data suggest that SSNa has potent anti-inflammatory activity in 3T3-L1 hypertrophied adipocytes.

$\mathrm{NF}-\kappa \mathrm{B}$, a family of transcription factors, regulates the expression of a number of immune-related cytotoxic factors, including iNOS and COX-2, and pro-inflammatory cytokines, including TNF $\alpha$, IL- $1 \beta$ and IL-6. The MAPK family also induces the production of immune-related cytotoxic factors and pro-inflammatory cytokines (31-33). NF- $\mathrm{KB}$ and MAPKs are well-recognized as targets of anti-inflammatory agents $(33,34)$. In this study, to elucidate the molecular mechanism of the inhibitory effect of SSNa on inflammatory mediators, we investigated the effects of SSNa on the activation of two signaling pathways, NF- $\mathrm{KB}$ and MAPK, in 3T3-L1 hypertrophied adipocytes. These results show that SSNa inhibits the NF- $\kappa B$ signaling pathway as a core regulator of inflammation through suppression of the phosphorylation of ERK (the downstream of $\mathrm{TNF} \alpha$ ) and $\mathrm{I} \kappa \mathrm{B} \alpha$, preventing NF- $\mathrm{B}$ translocation to the nucleus in 3T3-L1 hypertrophied adipocytes. However, activation of the JNK and p38 pathways did not have a greater effect than that of ERK (data not shown). These pathways were verified with U0126 (a specific inhibitor of ERK), i.e., a decrease of $\mathrm{NF}-\mathrm{\kappa B}$ translocation by treatment of SSNa. Thus, we consider 


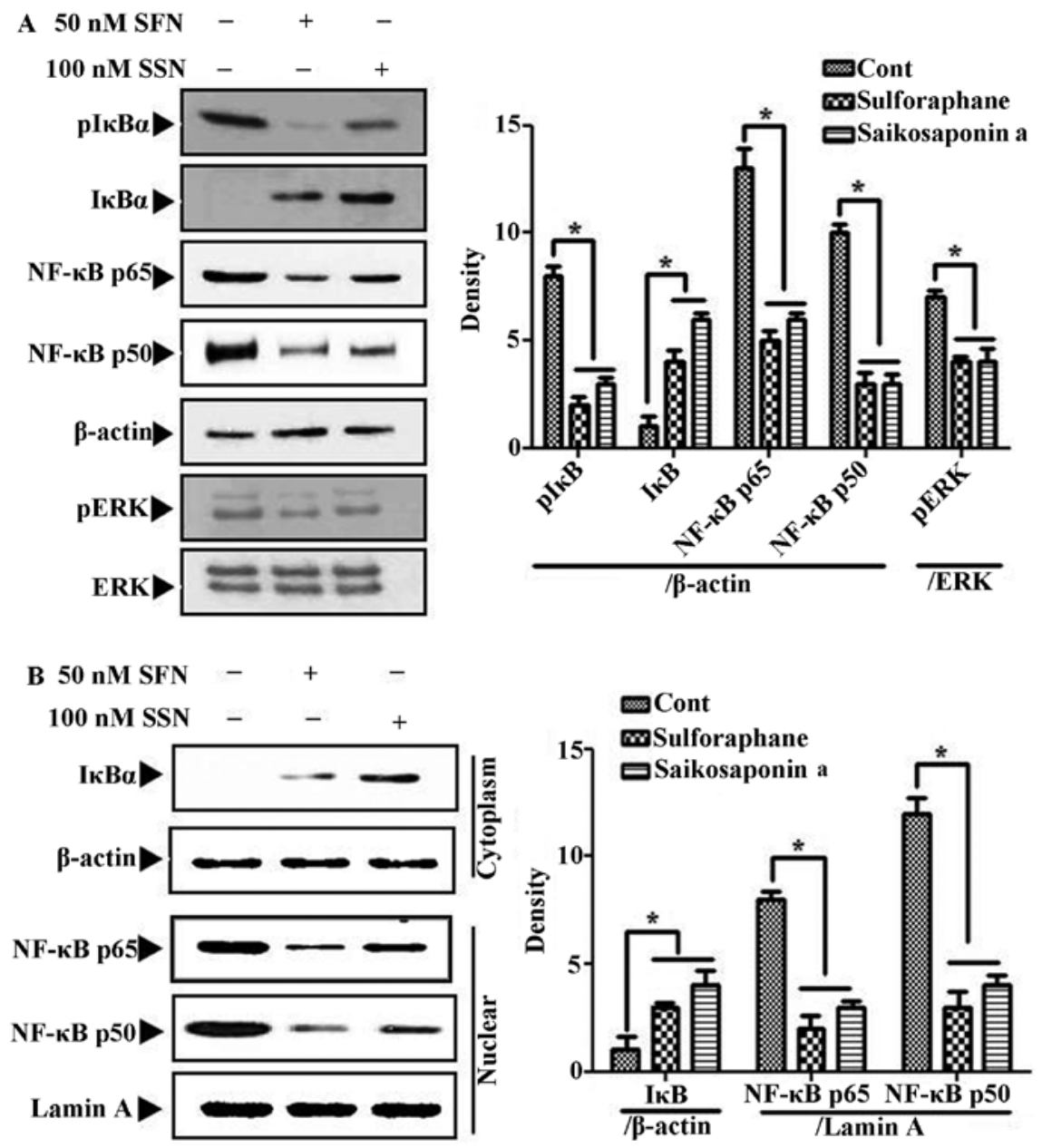

Figure 4. Effect of saikosaponin a (SSNa) on nuclear factor-kB cells (NF-kB) activation in 3T3-L1 hypretriphied adipocytes. (A) Following treatment with SSNa for $1 \mathrm{~h}$, total RNA was isolated and subjected to reverse transcription-polymerase chain reaction (RT-PCR) and the final PCR product was resolved using $1.5 \%$ agarose gel electrophoresis. Cell lysates were analyzed by western blot analysis. Glyceraldehyde 3-phosphate dehydrogenase (GAPDH) and $\beta$-actin were used as an internal control for RT-PCR and western blot analysis, respectively. (B) Nuclear and cytosolic fractions were extracted by commercial extraction kit. Each extract was prepared to determine the levels of p65, p50 and I $\mathrm{KB} \alpha$ by western blot analysis. $\beta$-actin was used as an internal control for the cytosolic fraction and lamin A was applied as an internal control for the nuclear fraction. Band intensities in the immunoblots were quantified by densitometry using L Process and Multi Gauge software. Band intensities were normalized relative to the internal control ( $\beta$-actin and lamin A) and background, respectively. Statistical significance (Student's t-test) analyses were performed using GraphPad Prism 5 ("p $<0.05$ vs. the untreated control). Each value indicates the mean \pm standard error of the mean (SEM) and is representative of results obtained from three independent experiments.

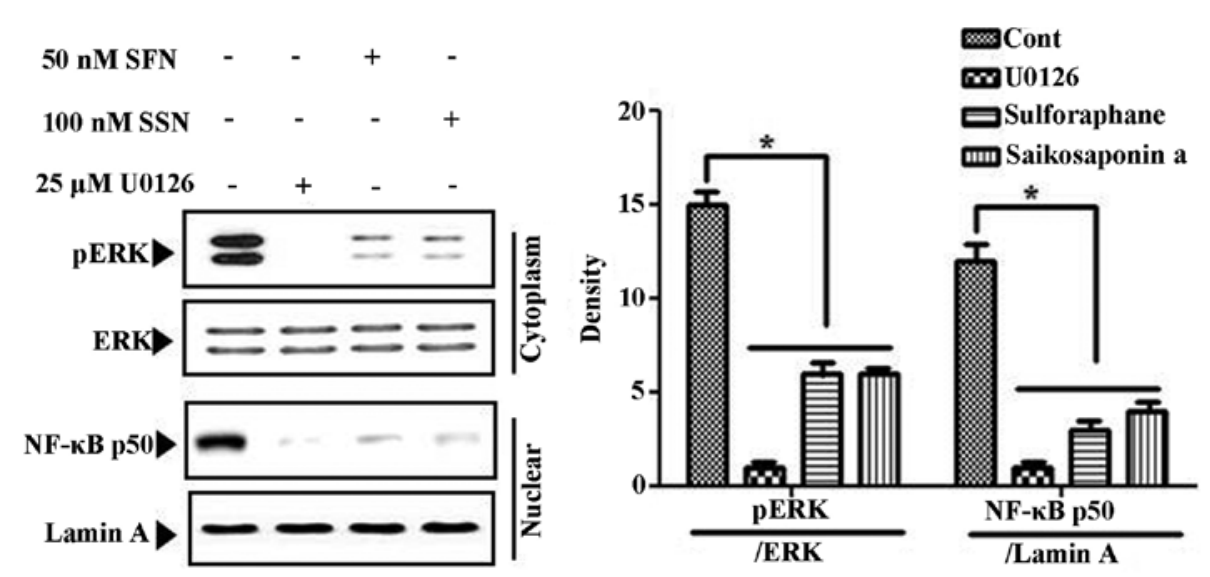

Figure 5. Inhibition of ERK axis with U0126 as ERK inhibitor-suppressed translocation of NF-кB into nuclear in 3T3-L1 hypertrophied adipocytes. Cells were pretreated for $30 \mathrm{~min}$ with U0126 and then treated with saikosaponin a (SSNa). Nuclear and cytosolic fractions were extracted by commercial extraction kit. Each extract was prepared to determine the levels of phospholyated ERK and NF- $\mathrm{kB}$ p50 by western blot analysis, respectively. Total ERK was used as an internal control for the cytosolic fraction and lamin A was applied as an internal control for the nuclear fraction. Band intensities in the immunoblots were quantified by densitometry using L Process and Multi Gauge software. Band intensities were normalized relative to the internal controls (total ERK and lamin A) and background, respectively. Statistical significance (Student's t-test) analyses were performed using GraphPad Prism 5 (" $\mathrm{p}<0.05$ vs. the untreated control). Each value indicates the mean \pm standard error of the mean (SEM) and is representative of results obtained from three independent experiments. 
that the anti-inflammatory effect of SSNa is associated with the inhibition of $\mathrm{NF}-\kappa \mathrm{B}$ translocation to the nucleus via an inhibitory effect on ERK signaling pathway.

In conclusion, these results show that SSNa can regulate the expression of proinflammatory and inflamatory-associated genes in 3T3-L1 hypertrophied adipocytes and is a potent inhibitor of $\mathrm{NF}-\kappa \mathrm{B}$ activation. Inhibition of the ERK pathway by $\mathrm{SSNa}$ prevents the induction of inflammation in hypertrophied adipocytes. Thus these results suggeste that $\mathrm{SSNa}$ serves as a novel therapeutic agent against obesity-associated inflammation. The anti-inflammatory effects of SSNa appear to be controlled through inhibition of the $\mathrm{NF}-\kappa \mathrm{B} / \mathrm{I} \kappa \mathrm{B}$ signaling cascade. However, future in vivo studies are required to precisely clarify the mechanisms of action of SSNa and its role in the relationship between activation of $\mathrm{NF}-\kappa \mathrm{B}$ and production of inflammatory cytokines in obese individuals.

\section{Acknowledgements}

This study was supported by the National Research Foundation of Korea (NRF) grant funded by the Korea government (MSIP) (No. 2011-0030124).

\section{References}

1. Korea Ministry of Health and Welfare: Annual report of obesity statistics in Korea in 2010. http://knhanes.cdc.go.kr, 2013.

2. Trayhurn P and Wood IS: Adipokines: inflammation and the pleiotropic role of white adipose tissue. Br J Nutr 92: 347-355, 2004.

3. Kershaw EE and Flier JS: Adipose tissue as an endocrine organ. J Clin Endocrinol Metab 89: 2548-2556, 2004.

4. Bastard JP, Jardel C, Bruckert, Blondy P, Capeau J, Laville M, Vidal $\mathrm{H}$ and Hainque B: Elevated levels of interleukin 6 are reduced in serum and subcutaneous adipose tissue of obese women after weight loss. J Clin Endocrinol Metab 85: 3338-3342, 2000.

5. Mohamed-Ali V, Flower L, Sethi J, Hotamisligil G, Gray R, Humphries SE, York DA and Pinkney J: beta-Adrenergic regulation of IL-6 release from adipose tissue: in vivo and in vitro studies. J Clin Endocrinol Metab 86: 5864-5869, 2001.

6. Loffreda S, Yang SQ, Lin HZ, Karp CL, Brengman ML, Wang DJ, Klein AS, Bulkley GB, Bao C, Noble PW, Lane MD and Diehl AM: Leptin regulates proinflammatory immune responses. FASEB J 12: 57-65, 1998.

7. Esposito K, Nappo F, Marfella R, Giugliano G, Giugliano F, Ciotola M, Quagliaro L, Ceriello A and Giugliano D: Inflammatory cytokine concentrations are acutely increased by hyperglycemia in humans: role of oxidative stress. Circulation 106: 2067-2072, 2002.

8. Kim JK, Oh SM, Kwon HS, Oh YS, Lim SS and Shin HK: Anti-inflammatory effect of roasted licorice extracts on lipopolysaccharide-induced inflammatory responses in murine macrophages. Biochem Biophys Res Commun 345: 1215-1223, 2006.

9. Lu CN, Yuan ZG, Zhang XL, Yan R, Zhao YQ, Liao M and Chen JX: Saikosaponin a and its epimer saikosaponin d exhibit anti-inflammatory activity by suppressing activation of NF- $\kappa \mathrm{B}$ signaling pathway. Int Immunopharmacol 14: 121-126, 2012.

10. Mendoza EE and Burd R: Quercetin as a systemic chemopreventative agent: structural and functional mechanisms. Mini Rev Med Chem 11: 1216-1221, 2011.

11. Lu XL, He SX, Ren MD, Wang YL, Zhang YX and Liu EQ: Chemopreventive effect of saikosaponin-d on diethylinitrosamine-induced hepatocarcinogenesis: involvement of CCAAT/enhancer binding protein $\beta$ and cyclooxygenase-2. Mol Med Rep 5: 637-644, 2012.

12. Wu GC, Wu H, Fan LY and Pan HF: Saikosaponins: a potential treatment option for systemic lupus erythematosus. Ir J Med Sci 180: 259-261, 2011.

13. Yang YY, Tang YZ, Fan CL, Luo HT, Guo PR and Chen JX: Identification and determination of the saikosaponins in Radix bupleuri by accelerated solvent extraction combined with rapid-resolution LC-MS. J Sep Sci 33: 1933-1945, 2010.
14. Eom HY, Park SY, Kim MK, Suh JH, Yeom H, Min JW, Kim U, Lee J, Youm JR and Han SB: Comparison between evaporative light scattering detection and charged aerosol detection for the analysis of saikosaponins. J Chromatogr A 1217: 4347-4354, 2010.

15. Sun Y, Cai TT, Zhou XB and Xu Q: Saikosaponin a inhibits the proliferation and activation of $T$ cells through cell cycle arrest and induction of apoptosis. Int Immunopharmacol 9: 978-983, 2009.

16. Ushio $\mathrm{Y}$ and Abe H: Inactivation of measles virus and herpes simplex virus by saikosaponin d. Planta Med 58: 171-173, 1992.

17. Rao GS and Sinsheimer JE: Antiviral activity of triterpenoid saponins containing acylated beta-amyrin aglycones. J Pharm Sci 63: 471-473, 1974.

18. Yamamoto M, Kumagai A and Yamamura Y: Structure and actions of saikosaponins isolated from Bupleurum falcatum L. I. Anti-inflammatory action of saikosaponins. Arzneimittelforschung 25: 1021-1023, 1975.

19. Aggarwal BB: Targeting inflammation-induced obesity and metabolic diseases by curcumin and other nutraceuticals. Annu Rev Nutr 21: 173-199, 2010.

20. Nieto-Vazquez I, Fernandez-Veledo S, Krämer DK, Vila-Bedmar R, Garcia-Guerra L and Lorenzo M: Insulin resistance associated to obesity: the link TNF-alpha. Arch Physiol Biochem 114: 183-194, 2008.

21. Weisberg SP, McCann D, Desai M, Rosenbaum M, Leibel RL and Ferrante AW Jr: Obesity is associated with macrophage accumulation in adipose tissue. J Clin Invest 112: 1796-1808, 2003.

22. Bulló M, Casas-Agustench P, Amigó-Correig P, Aranceta J and Salas-Salvadó J: Inflammation, obesity and comorbidities: the role of diet. Public Health Nutr 10: 1164-1172, 2007.

23. Gregoire FM, Smas CM and Sul HS: Understanding adipocyte differentiation. Physiol Rev 78: 783-809, 1998.

24. Reader J, Holt D and Fulton A: Prostaglandin E2 EP receptors as therapeutic targets in breast cancer. Cancer Metastasis Rev 30: 449-463, 2011.

25. Zhang J and Rivest S: Anti-inflammatory effects of prostaglandin $\mathrm{E} 2$ in the central nervous system in response to brain injury and circulating lipopolysaccharide. J Neurochem 76: 855-864, 2001.

26. Jung CH, Kim JH, Park S, Kweon DH, Kim SH and Ko SG: Inhibitory effect of Agrimonia pilosa Ledeb. on inflammation by suppression of iNOS and ROS production. Immunol Investi 39: 159-170, 2010.

27. Mohy El-Din MM, Senbel AM, Bistawroos AA, El-Mallah A, Nour El-Din NA, Bekhit AA and Abd El Razik HA: A novel COX-2 inhibitor pyrazole derivative proven effective as an anti-inflammatory and analgesic drug. Basic Clin Pharmaco Toxicol 108: 263-273, 2011.

28. Zhang HH, Halbleib M, Ahmad F, Manganiello VC and Greenberg AS: Tumor necrosis factor-alpha stimulates lipolysis in differentiated human adipocytes through activation of extracellular signal-related kinase and elevation of intracellular cAMP. Diabetes 51: 2929-2935, 2002.

29. Nonogaki K, Fuller GM, Fuentes NL, Moser AH, Staprans I, Grunfeld $\mathrm{C}$ and Feingold KR: Interleukin-6 stimulates hepatic triglyceride secretion in rats. Endocrinology 136: 2143-2149, 1995.

30. Abe H, Sakaguchi M and Arichi S: [Pharmacological studies on a prescription containing Bupleuri Radix (IV). Effects of saikosaponin on the anti-inflammatory action of glucocorticoid]. Nihon Yakurigaku Zasshi 80: 155-161, 1982 (In Japanese).

31. Wang SL, Li Y, Wen Y, Chen YF, Na LX, Li ST and Sun CH: Curcumin, a potential inhibitor of up-regulation of TNF-alpha and IL-6 induced by palmitate in 3T3-L1 adipocytes through NF-kappaB and JNK pathway. Biomed Environ Sci 22: 32-39, 2009.

32. Gonzales AM and Orlando RA: Curcumin and resveratrol inhibit nuclear factor-kappaB-mediated cytokine expression in adipocytes. Nutr Metab (Lond) 5: 1-13, 2008.

33. Kyriakis JM and Avruch J: Mammalian MAPK signal transduction pathways activated by stress and inflammation: a 10-year update. Physiol Rev 92: 689-737, 2012.

34. DiDonato JA, Mercurio F and Karin M: NF- $\kappa B$ and the link between inflammation and cancer. Immunol Rev 246: 379-400, 2012. 